\title{
Effect of vanadium ion valence state on the deposition behaviour in molten salt electrolysis
}

\author{
Joachim Gussone ${ }^{\mathrm{a}, \mathrm{z}}$, Chakradhar Reddy Yerragudi Vijay, Jan Haubrich ${ }^{\mathrm{a}}$, Ksenija Milicevic ${ }^{\mathrm{b}}$, \\ Bernd Friedrich $^{\mathrm{b}}$
}

${ }^{\mathrm{a}}$ Institute of Materials Research, German Aerospace Center (DLR), Linder Höhe, D-51147 Cologne, Germany

${ }^{\mathrm{b}}$ IME Process Metallurgy and Metal Recycling, RWTH Aachen University, Intzestr. 3, D-52072 Aachen,

Germany

ze-mail: joachim.gussone@dlr.de

Telephone: +4922036012606

Fax: +492203696480

Keywords: Electrodeposition, molten salt, valence state, vanadium

\begin{abstract}
The electrodeposition process of vanadium from $\mathrm{LiCl}-\mathrm{KCl}$ base electrolytes was investigated by means of cyclic voltammetry, galvanostatic electrolyses and micro analytical analysis of the deposits. It is demonstrated that the valence state of the vanadium ions has a critical influence on the feasibility of performing a reproducible and stable coating process aiming to obtain compact vanadium films. When the electrolyte contained predominantly trivalent vanadium ions, the process was unstable and the deposit consisted of dendrites. In contrast, making use of a comproportionation reaction of metallic vanadium and $\mathrm{VCl}_{3}$ to divalent vanadium ions led to a stable deposition behaviour and allowed to obtain thick deposits with high current efficiencies. The disadvantageous behaviour of melts with mostly trivalent ions is explained by the fact that deposition is interfered by the reduction of trivalent to divalent ions under limiting current conditions.
\end{abstract}




\section{$1 \quad$ Introduction}

Vanadium is rarely used in its pure metallic condition. A few applications such as sputter targets or thin vanadium foils to bond titanium to steel are reported [1]. Vanadium alloys like e.g. V-4Cr-4Ti are being developed for nuclear industry and considered to be suitable materials for fusion reactors [2]. However, most of the metallic vanadium (ca. 85\% [3]) serves as alloying element for steel production (ferrovanadium). Besides aluminium it is the most important alloying element for $\alpha+\beta$-titanium alloys (e.g. Ti-6Al-V4) and metastable $\beta$ titanium alloys (e.g. Ti-15V-3Cr-3Al-3Sn) [4]. Vanadium can be produced by several methods from its compounds such as calciothermic or aluminothermic reduction [1]. Since the products of these processes generally do not exhibit sufficient purity levels, molten salt electrolyses have been studied as refining step [5-8], e.g. for vanadium prepared by carbothermic reduction of $\mathrm{V}_{2} \mathrm{O}_{5}$. Yet it was reported, that through refining electrolysis, high purity vanadium formed at the cathode as large dendrites [5].

Literature on the nature and behaviour of vanadium metal and its ionic species in molten salts is very limited. In one recent publication [9], a study on the electrochemistry of vanadium in $\mathrm{NaCl}-\mathrm{KCl}$ melts with various methods has been reported, including anodic dissolution, oxidation and reduction reactions of trivalent and divalent vanadium ions as well as the electrodeposition process. Furthermore, the structure of ionic vanadium species has been characterised in different studies $[10,11]$ by means of absorption spectroscopy.

However, to our knowledge, there is no information published dealing with the electrodeposition of compact and uniform vanadium layers, which is in contrast to other transition metals like titanium [12] or niobium [13]. One relevant application for such a coating process is the deposition of vanadium films on steel parts for bonding steel to titanium, removing the necessity of foils with the required dimensions (see above, [1]). 
A further task is the coating of fibres for the production of metal matrix composites (MMC) according to the matrix coated fibre route $[14,15]$. In this context the co-deposition together with titanium is of special interest and object of ongoing research.

The long-term objective of the work presented here is to establish fundamentals for the development of alloy deposition processes consisting of anodic dissolution [16] and codeposition of the constituents for titanium alloys like Ti-6Al-4V.

\section{Experimental}

The molten salt experiments were carried out in a glovebox system (Jacomex) under high purity Argon atmosphere $\left(\mathrm{O}_{2}, \mathrm{H}_{2} \mathrm{O}<1 \mathrm{ppm}\right)$. All chemicals, electrodes and crucibles were stored and used within the glovebox in order to minimize contaminations, i.e. especially water pick-up of the highly hygroscopic chemicals or the introduction of oxygen.

The molten salt reactor was attached to the base of the glovebox. A miniaturized experimental setup was employed for this study with a small glassy carbon (GC) crucible (GAT2, HTW, Sigradur G), thin electrodes and small amounts of salts (approx. $10 \mathrm{~g}$ per experiment). Within this experimental framework and precautions it was possible to use high purity anhydrous $\mathrm{KCl}$ (Alfa Aesar, ultra dry, $99.95 \%$ metals basis) and LiCl (Alfa Aesar, ultra dry, $99.9 \%$ metals basis) without further treatment. $\mathrm{VCl}_{3}$ (Alfa Aesar, $99.0 \%$ ) served as vanadium source and was added to the salt mixture before melting.

Thin tungsten wires $\left(d_{\mathrm{W}}=0.15 \mathrm{~mm}\right)$ were chosen as working electrodes (WE) because they have a similar diameter as the SiC fibres (SCS6, Specialty Materials) so that the suitability for the production of MMC could be verified. Tungsten rods $(\varnothing=0.5 \mathrm{~mm}$, Alfa Aesar, $99.95 \%)$ were also used as counter electrodes (CE). The Glassy carbon crucible served also as quasi reference electrode (QRE). 
Eutectic mixtures of $\mathrm{LiCl}-\mathrm{KCl}$ were used as electrolyte with additions of $0.34 \mathrm{~mol} \% \mathrm{VCl}_{3}$ at process temperatures of approx. $700 \mathrm{~K}$. For the experiments with divalent vanadium ions, a metallic vanadium wire (99.5\%, Alfa Aesar) was added to the electrolyte and was in contact with the crucible. All electrochemical experiments were carried out with a BANK HC400 potentiostat/galvanostat.

After the experiments the electrodes were cleaned with deionized water and dried subsequently. The morphologies of the deposits were investigated using Zeiss Ultra 55 scanning electron microscope (SEM) equipped with energy dispersive X-ray spectroscopy (EDS) technique. The diameter $(d)$ and coating length $(L)$ of the plated wires were determined with a stereo microscope (Zeiss Discovery.V12) with the image evaluation software AxioVision SE64.

\section{$3 \quad$ Results}

\section{1. $\quad$ Electrochemical measurements}

In a comparative study cyclic voltammetry (CV) measurements with tungsten working electrodes were carried out in $\mathrm{LiCl}-\mathrm{KCl}$ melts with $0.34 \mathrm{~mol} \% \mathrm{VCl}_{3}$, both with and without $\mathrm{V}$ metal addition. The investigation covers a large potential window enabling us to study the electrochemical reactions related to vanadium ions occurring in this range. In both systems the reverse potential $\left(E_{\text {rev }}\right)$ was chosen positive enough to include the onset of chlorine evolution as internal reference, as proposed e.g. by Berghoute et al. [17].

Cyclic voltammograms recorded in $(\mathrm{LiCl}-\mathrm{KCl})_{\text {(eut.) }}-0.34 \mathrm{~mol} \% \mathrm{VCl}_{3}$ melt (Figure 1 , without V metal addition) exhibited current peaks, which can be attributed to the following reactions [9]: The current peaks R1 and O1 correspond to the electrodeposition of divalent ions and its anodic dissolution process (eq. 1). There is a moderate current increase beginning at $-650 \mathrm{mV}$ 
$\left(-1640 \mathrm{mV}\right.$ vs. $\left.\mathrm{Cl}_{2} / \mathrm{Cl}^{-}\right)$before the current increases steeply at $-1030 \mathrm{mV}(-2020 \mathrm{mV}$ vs. $\left.\mathrm{Cl}_{2} / \mathrm{Cl}^{-}\right)$.

$\mathrm{V}^{2+}+2 \mathrm{e}^{-} \leftrightarrow \mathrm{V}$

Furthermore, the oxidation of divalent vanadium ions (process $\mathrm{O} 2$ ) as well as the reduction (R2) of trivalent vanadium ions by single-electron transfers was observed (eq. 2):

$\mathrm{V}^{3+}+1 \mathrm{e}^{-} \leftrightarrow \mathrm{V}^{2+}$

The mid-peak potential $\left(E_{\mathrm{mid}}\right)$ of this reaction is approx. $-126 \mathrm{mV}$ (ca. $-1100 \mathrm{mV}$ vs. $\mathrm{Cl}_{2} / \mathrm{Cl}^{-}$), i.e. more negative than the potential of the GC-QRE, because predominately $\mathrm{V}^{3+}$ ions are present in the electrolyte. This is also supported by the fact that during the first positive scan of the CV experiment (Figure 1, dotted line), which consisted of a total of three cycles, no clear current increase that can be related to oxidation according to eq. 2 was observed since most of the vanadium ions were already trivalent.

At the positive potential $E_{\text {rev }}$ chlorine evolution (O3) occurs. As mentioned above, this reaction served as internal reference to estimate the potential of the reaction $\left(\mathrm{Cl}_{2} / \mathrm{Cl}^{-}\right)$and allows a comparison with literature data. However, the reproducibility and the currentpotential characteristics (i.e. the shapes of the voltammograms in this system), especially of the deposition of vanadium (R1), render further evaluation problematic.

In contrast, reproducible and consistent results were achieved in $(\mathrm{LiCl}-\mathrm{KCl})_{(\text {eut.) }}-\mathrm{VCl}_{3}$ with $\mathrm{V}$ metal addition: The CV measurement shown in Figure 2 includes 3 cycles which have almost exactly the same curve progressions with two oxidation and reduction processes of vanadium (O1, $\mathrm{O} 2$ and $\mathrm{R} 1, \mathrm{R} 2)$. The $\mathrm{CV}$ measurements confirm that divalent vanadium ions have been generated by comproportionation of $\mathrm{V}^{3+}$ and $\mathrm{V}(0)$ (eq. 3) [11], because in this electrolyte system the potential of the QRE is established by the reaction $\mathrm{V} / \mathrm{V}^{2+}$ due to its contact to 
metallic $\mathrm{V}$ and divalent ions. It is close to the stationary potential $\left(-1955 \mathrm{mV}\right.$ vs. $\left.\mathrm{Cl}_{2} / \mathrm{Cl}^{-}\right)$of vanadium reported for $\mathrm{NaCl}-\mathrm{KCl}$ at $698^{\circ} \mathrm{C}[9]$.

$2 \mathrm{~V}^{3+}+\mathrm{V} \rightarrow 3 \mathrm{~V}^{2+}$

In this system the same electrochemical reactions $\mathrm{V} / \mathrm{V}^{2+}$ and $\mathrm{V}^{2+} / \mathrm{V}^{3+}$ as in $\left.(\mathrm{LiCl}-\mathrm{KCl})_{(\text {eut. }}\right)^{-}$ $\mathrm{VCl}_{3}$ without $\mathrm{V}$ metal addition have been observed. The potential $E_{\text {mid }}\left(\mathrm{V}^{3+} / \mathrm{V}^{2+}\right)$ is approx. $1060 \mathrm{mV}$ and very close to the formal standard potential value $(-1070 \mathrm{mV})$ reported for $450^{\circ} \mathrm{C}$ in $\mathrm{LiCl}-\mathrm{KCl}$ [18]. The peak separation $E_{\mathrm{p}}(\mathrm{O} 2)-E_{\mathrm{p}}(\mathrm{R} 2)$ is approx. $150 \mathrm{mV}$, which is only slightly higher than the theoretical value for ions having a reversible reaction $(\Delta E=2.22$ $\times R T /(1 F)=134 \mathrm{mV}[19])$, and the peak current densities of reduction and oxidation show similar values $\left(i_{\mathrm{p}}(\mathrm{R} 2) / i_{\mathrm{p}}(\mathrm{O} 2) \approx 1\right)$. The electrodeposition process $\mathrm{V}^{2+} / \mathrm{V} /$ (eq. 1$)$ has been investigated in further experiments (Figure 3), in which in particular the scan rate was varied. Since $i_{\mathrm{p}}$ and $v^{1 / 2}$ showed a quite linear relationship (Figure 3b), electrodeposition (R1) might be a reversible, diffusion controlled reaction. However, there is a distinct shift of $E_{\mathrm{p}}$ when the scan rate exceeds $0.2 \mathrm{~V} / \mathrm{s}$ (Figure $3 \mathrm{c}$ ) and $\Delta E=E_{\mathrm{p}}(\mathrm{R} 1)-E_{\mathrm{p} / 2}(\mathrm{R} 1)$ increases from ca. $-40 \mathrm{mV}$ to $-60 \mathrm{mV}$. This is higher than the theoretical value for reversible reactions involving the formation of insoluble products $(\Delta E=-0.77 \times R T /(2 F)=-23 \mathrm{mV}$ [20]). Furthermore, the formal standard potential calculated for reversible metal deposition $\left(E^{\prime}=E_{\mathrm{p}}-R T /(2 F) \times \ln C_{\mathrm{V}}\right.$ $+0.85 R T /(2 F)[8,21])$ is approx. $-1970 \mathrm{mV}$, which is considerably more negative than the literature value (-1855 $\mathrm{mV}$ [18]). Since not all criteria for reversible reactions are fulfilled, a quasi-reversible behaviour may be assumed for the electrodeposition process.

Further reactions such as $\mathrm{V}^{3+} / \mathrm{V}^{4+}$ considered by Polovov et al. [9] were not observed in our experiments. As already reported elsewhere, higher oxidation states $\left(\mathrm{V}^{4+}\right.$ and $\left.\mathrm{V}^{5+}\right)$ can be expected in the presence of oxygen $[10,11]$. 
Altogether we observed in both systems two electrochemical reactions related to the vanadium ions. The reduction of trivalent vanadium ions having a reversible behaviour was found in the electrolyte system with predominantly divalent vanadium ions, while for the electrodeposition not all criteria for reversible reactions were fulfilled.

\subsection{Electrodeposition of vanadium}

Electrodeposition experiments have been conducted galvanostatically in both electrolyte systems for 30-120 minutes in order to characterize the stability of the deposition process over elongated periods, finding that the $\mathrm{V}$ metal addition leads to a much more stable process. Examples of representative electrolyses are depicted in Figure 4. In these experiments, the chosen current $I=1 \mathrm{~mA}$ corresponded to initial current densities $\left(i_{\text {start }}\right)$ of ca. $39 \mathrm{~mA} \mathrm{~cm}^{-2}$ in the case of $(\mathrm{LiCl}-\mathrm{KCl})_{\text {(eut.) }}-0.34 \mathrm{~mol}_{0} \mathrm{VCl}_{3}$ and $i_{\text {start }}=47 \mathrm{~mA} \mathrm{~cm}{ }^{-2}$ in the electrolyte system with $\mathrm{V}$ metal addition due to slightly different immersion length of the tungsten wires. The evolution of the measured potentials differ strongly between both systems: In the system without $\mathrm{V}$ metal addition there are very strong fluctuations around ca. - $770 \mathrm{mV}$ vs. QRE and the potential shows a shift towards less negative values. This behaviour generally indicates an increase in the surface area due to rougher morphology (e.g. needles or dendrites). As a consequence the current density and the negative polarisation of the electrode decrease. In contrast, the potential of the electrode in the system with $\mathrm{V}$ metal addition is very stable throughout the whole deposition process (between $-80 \mathrm{mV}$ and $-90 \mathrm{mV}$ vs. QRE).

A comparison of the potentials related to $E\left(\mathrm{Cl}_{2} / \mathrm{Cl}^{-}\right)$determined based on the preceding $\mathrm{CV}$ measurements (Figure 1 and Figure 2) indicates that the potential of the deposition process in the system with $\mathrm{V}$ metal (i.e. with predominantly divalent vanadium ions) is considerably more negative (see additional ordinates on the right side of the diagram in Figure 4). Without $\mathrm{V}$ addition a more positive potential arises because two competing reactions take place: the 
reduction $\mathrm{V}^{3+} / \mathrm{V}^{2+}$ according to eq. 2 at considerably more positive potentials (see section 3.1), and the electrodeposition process.

Recapitulating the galvanostatic experiments, we can conclude that the presence of predominantly divalent vanadium ions is crucial for a stable electrodeposition process.

\subsection{Characterisation of the vanadium deposits}

The deposit obtained from $(\mathrm{LiCl}-\mathrm{KCl})_{(\text {eut. })}-0.34 \mathrm{~mol} \% \mathrm{VCl}_{3}$ consists mainly of irregularly distributed dendrites (Figure 5a), i.e. stalks with three-dimensional branch structures [22] (Figure 5b). The observation of dendrites supports the assumption that material losses by detachment from the cathode may have been responsible for fluctuations of the potential (Figure 4). Dendrite formation causing an increase of the electrode's surface area may also explain the potential drift towards less negative potentials observed during the electrodeposition experiment (Figure 4).

A thick massive coating was deposited from the electrolyte with vanadium metal addition (Figure $5 \mathrm{c}, \mathrm{d})$. The thickness of the vanadium layer grown within $30 \mathrm{~min}$ under galvanostatic conditions $(1 \mathrm{~mA})$ is approx. $35 \mu \mathrm{m}$ (Figure 5c.). Large well-crystallized grains with smooth crystal planes and grain sizes exceeding $50 \mu \mathrm{m}$ can be recognized (Figure 5d). In longer deposition experiments $(120 \mathrm{~min})$ also coating thicknesses up to more than $100 \mu \mathrm{m}$ could be achieved.

According to EDS measurements both deposits consist mainly of vanadium. Small amounts of chlorine have been detected only in the case of the dendritic deposits from ( $\mathrm{LiCl}-\mathrm{KCl})_{\text {(eut.) }}$ $0.34 \mathrm{~mol} \% \mathrm{VCl}_{3}$ without vanadium metal addition due to electrolyte entrapment.

Altogether, the SEM investigations are consistent with the observations during the electrodeposition experiments, i.e. the stable process conditions, observed in the electrolyte system with predominantly divalent vanadium ions, led to favourable deposits. 


\subsection{Estimation of the current efficiency}

The formation of coherent vanadium films with comparatively uniform coating thicknesses from the electrolyte system with vanadium metal addition, allows us to estimate the current efficiency based on the thickness of the deposit. The diameter of the coated wires varied between ca. $210 \mu \mathrm{m}$ and $350 \mu \mathrm{m}$ depending on the immersion length $L$ of the tungsten wire and the duration of the electrodeposition process $(30-120 \mathrm{~min})$. By measuring the diameters $d$ of the coated wires, the volume of the deposited material was determined $\left(V_{\text {coat }}=\pi L\left(d^{2}-\right.\right.$ $\left.d_{\mathrm{w}}^{2}\right)$ /4). The corresponding mass ( $\left.m_{\text {coat }}\right)$ was compared to the mass calculated from Faraday's law $\left(m_{\text {calc }}\right)$ with the assumption that 2 electrons $(z=2)$ per vanadium ion have been transferred according to eq. 4 .

$\varepsilon=\frac{\pi L\left(d^{2}-d_{\mathrm{w}}^{2}\right) z F \rho_{\mathrm{V}}}{4 M_{\mathrm{V}} I t}$

Current efficiency values between 96 and $110 \%$ (Table 1) provide a further strong indication that indeed predominantly divalent vanadium ions are the responsible ion for deposition and prove their existence in the electrolyte. Furthermore, neither material loss due to incoherent deposits [23] nor foil formation, as observed e.g. in electrolytes with titanium ions [14, 24], caused reduced efficiencies.

\subsection{Inspection of solidified electrolyte}

After the electrodeposition experiments the solidified salts of the electrolytes were removed from the crucible and crushed within the glovebox under Argon atmosphere (Figure 6) for chemical analysis. The different colours that were subsequently found can be explained by the oxidation state of the vanadium ions. No information about the colour of electrolytes containing trivalent vanadium ions was found, but it is reported in literature that trivalent titanium ions cause a purple colour [23] in $\mathrm{LiCl}-\mathrm{KCl}$, which would suit to the colour of $(\mathrm{LiCl}-\mathrm{KCl})_{\text {(eut.) }}-0.34 \mathrm{~mol}^{2} \mathrm{VCl}_{3}$ (Figure 6a) taking into account the low concentrations in 
the present study. According to Polovov et al. [25] divalent vanadium ions caused grey to green colours in $\mathrm{NaCl}-\mathrm{KCl}$ depending on the concentration. Assuming that a complete conversion of $\mathrm{V}^{3+}$ to $\mathrm{V}^{2+}$ has taken place (eq. 3) in the system with vanadium addition, the electrolyte contained approx. $0.51 \mathrm{~mol} \% \mathrm{~V}^{2+}$ (ca. $0.75 \mathrm{wt} \%$ ). For this concentration a grey colour was found in the aforementioned study [25], whereas we observed a pale yellow to vaguely green colour (Figure 6b). However, due to the subjectivity of such classifications and the fact that it is not clear whether the colour of the molten or solidified melt was described [25], we cannot determine or resolve a contradiction between both studies. We conclude that the colours of the electrolytes provide a further qualitative indication for the change of the average valence state of vanadium.

\section{Discussion}

The experiments demonstrate the crucial impact of the valence state of the vanadium ions on the quality of the deposits. Due to the presence of the metallic vanadium wire, divalent vanadium ions were generated and stabilized by reaction of vanadium with $\mathrm{V}^{3+}$ (eq. 3 ). Furthermore, the depletion of $\mathrm{V}^{2+}$ from the bath due to the cathodic process is compensated by the supply of $\mathrm{V}^{2+}$ from the added vanadium metal which reacts again with the $\mathrm{V}^{3+}$ formed in the anodic reaction (Figure $7 \mathrm{a})$.

Trivalent ions are less favourable for electrodeposition since the initially dominating reaction that takes place at the cathode is the reduction to divalent ions (eq. 2). As the limiting current density of this reaction is exceeded, the potential changes drastically towards more negative values and additionally electrodeposition takes place. The deposition process reduces the concentration of $\mathrm{V}^{2+}$ at the electrode (Figure $7 \mathrm{~b}$ ). If the current density is high enough, the deposition takes place at limiting current from trivalent ions diffusing to the electrode, and the electrolyte is completely depleted of $\mathrm{V}^{2+}$. The observation of two competing reactions (reduction of $\mathrm{V}^{3+}$ and electrodeposition from $\mathrm{V}^{2+}$ or $\mathrm{V}^{3+}$ in Figure 7, represented by reaction 
$\mathrm{V}^{\mathrm{x}+}+\mathrm{x} \mathrm{e}^{-} \rightarrow \mathrm{V}$ ) is consistent with the measured potential fluctuations-/oscillations (Figure 4), as the local current densities constantly change during the electrolysis and also the potential which is enforced by the constant current $(1 \mathrm{~mA})$. This may even lead to potentials that are less negative than the potential required for electrodeposition, implicating lacking cathodic protection and, therefore, a partial dissolution of the deposit by comproportionation with $\mathrm{V}^{3+}$ (eq. 3), until the current density rises again due to the reduced surface area. In the present case, the partial dissolution of vanadium metal may be co-responsible for the material loss (detachment of the dendrites, Figure $7 b$ ). In addition to the discussed disadvantages of the trivalent ions, in the system without vanadium metal chlorine gas is formed at the anode, while the electrolyte is depleted of vanadium ions during the electrodeposition process (Figure 7b).

\section{Conclusions}

The results demonstrate the beneficial influence of the divalent oxidation state of the vanadium ions for a stable deposition process: The deposition of thick compact coatings was successfully realized from $(\mathrm{LiCl}-\mathrm{KCl})_{(\text {eut. })}-0.34 \mathrm{~mol}^{\circ} \mathrm{VCl}_{3}$ after metallic vanadium was added to the electrolyte. Electrodeposition experiments had high current efficiencies ( $>95 \%)$, which is a further requirement for reproducible coating processes. The results of this study enable developing a fibre coating process for the production for metal matrix composites. Especially the co-deposition of titanium, vanadium and aluminium are of interest and object of our future investigation.

\section{Acknowledgements:}

We thank the German Research Foundation (Deutsche Forschungsgesellschaft, DFG) for financially supporting the project (HA 4397/6-1, FR 1713/23-1). 


\section{References:}

1. Baroch EF (2000) Vanadium and vanadium alloys. Kirk-Othmer Encyclopedia of Chemical Technology, John Wiley \& Sons, Inc.

2. Muroga T (2016) Vanadium for nuclear systems. Reference Module in Materials Science and Materials Engineering, Elsevier

3. Moskalyk RR, Alfantazi AM (2003) Processing of vanadium: a review, minerals engineering 16 (9): 793-805

4. Peters M, Leyens C (2002) Titan und Titanlegierungen, Wiley VCH, Weinheim.

5. Lei KPV, Sullivan TA (1971) Electrorefining of vanadium prepared by carbothermic reduction of $\mathrm{V}_{2} \mathrm{O}_{5}$. Metall Trans 2: 2312-2134

6. Baker DH, Ramsdell JD (1960) Electrolytic vanadium and its properties J Electrochem Soc 107(12): 985-989

7. Tripathy PK, Sehra JC, Bose DK, Singh RP (1996) Electrodeposition of vanadium from a molten salt bath. J Appl Electrochem 26 (8): 887-890

8. Kazakova OS, Kuznetsov SA (2012) Electrochemical behavior and electrorefining of vanadium in melts containing titanium salts. ECS Transactions 50(11): 181-190

9. Polovov IB, Tray ME, Chernyshov MV, Volkovich VA, Vasin BD, Rebrin OI (2014) Electrode processes in vanadium-containing chloride melts. In: Gaune-Escard M, and Haarberg GM (Eds) Molten Salt Chemistry and Technology, Wiley, Hoboken, pp 257281.

10. Gruen D, McBeth R (1962) Absorbtion spectra of the II, III, IV and V oxidation states of vanadium in $\mathrm{LiCl}-\mathrm{KCl}$ eutectic octahedral-tetrahedral transformations of $\mathrm{V}$ (II) and V (III). J Phys Chem 66(1): 57-65.

11. Chernyshov MV, Polovov IB, Volkovich VA, Vasin BD, Rebrin OI, Vonogradov KV, Griffiths TR (2010) Electronic absorption spectra of vanadium species in halide melts. ECS Transactions 33 (7): 287-296. 
12. Wei D, Okido M, Oki T (1994) Characteristics of titanium deposits by electrolysis in molten chloride-fluoride mixture. J Appl Electrochem 24(9): 923-929.

13. Gillesberg B, Barner JHV, Bjerrum NJ, Lantelme F (1999) Niobium plating processes in alkali chloride melts. J Appl Electrochem 29(8): 939-949.

14. Gussone J, Hausmann J (2011) Deposition of titanium on SiC fibres from chloride melts, J Appl Electrochem 41(6): 657-662.

15. Chen Z, Li S, Wang Y, Li W, Wei C, Kong W, Jia X, Pei Q, Zhang W (2016) Electrochemical deposition of magnesium on SiC fibers from the $\mathrm{LiCl}-\mathrm{KCl}-\mathrm{MgCl}_{2}$ molten salt. J Electrochem Soc 9(163): 522-525

16. Milicevic K, Friedrich B, Gussone J, Haubrich J (2017) Anodic dissolution of vanadium in molten $\mathrm{LiCl}-\mathrm{KCl}-\mathrm{TiCl}_{2}$. J Appl Electrochem 47(5): 573-581

17. Berghoute Y, Salmi A, Lantelme F (1994) Internal reference systems for fused electrolytes. J Electroanal Chem 365(1-2): 171-177

18. Plambeck JA (1967) Electromotive force series in molten salts, J Chem Eng Data 12(1): $77-82$

19. Bard AJ, Faulkner LR (2001) Electrochemical methods, fundamentals and applications. 2 edn. John Wiley \& Sons, New York.

20. Mamantov G, Manning DL, Dale JM (1965) Reversible deposition of metals on solid electrodes by voltammetry with linearly varying potential. J Electroanal Chem 9(4): $253-259$

21. Berzins T, Delahay P (1953) Oscillographic polarographic waves for the reversible deposition of metals on solid electrodes. J Am Chem Soc 75(3): 555-559

22. Wranglén G (1960) Dendrites and growth layers in the electrocrystallization of metals, Electrochim Acta 2(1-3): 130-143 
23. Cordner GDP, Worner HW (1951) Electrolytic preparation of titanium. Aust J Appl Sci 2: 358-367

24. Kühnl H, Ehrlich P, Uihlein RD (1960) Die Abscheidung von Titanmetall durch Schmelzelektrolyse mit löslicher Anode. Z anorg allg Chem 306 (5-6): 246-259

25. Polovov IB, Vasin BD, Abakumov AV, Rebrin OI, Chernyshov MV, Volkovich VA, Griffiths TR (2007) Thermodynamics of the formation of vanadium(II) complexes in chloride melts. ECS Transactions 3(35): 589-597 


\section{Figure caption:}

Figure 1: Cyclic voltammogram recorded in $\left.\mathrm{LiCl}-\mathrm{KCl}_{(\text {eut.) }}\right)^{-} 0.34 \mathrm{~mol} \% \mathrm{VCl}_{3}$ using a tungsten wire as WE at ca. $700 \mathrm{~K}$. The dotted (red) curve is the first positive scan, in which no considerable current increase could be observed before chlorine evolution (O3), demonstrating that the vanadium ions in the melt are predominantly in the trivalent state.

Figure 2: Cyclic voltammogram recorded in $\mathrm{LiCl}_{-\mathrm{KCl}_{\text {(eut. })}}-0.34 \mathrm{~mol} \% \mathrm{VCl}_{3}$ using a tungsten wire as WE at ca. $700 \mathrm{~K}$. A metallic V wire was added to the electrolyte in order to generate divalent vanadium ions. In contact with the GC crucible it determines the potential of the reference electrode (V,GC-QRE) .

Figure 3: Voltammetric investigation of electrodeposition process in $\mathrm{LiCl}-\mathrm{KCl}_{(\text {(eut.) }}-0.34$ mol\% $\mathrm{VCl}_{3}$ with $\mathrm{V}$ metal addition using tungsten wire as $\mathrm{WE}$ at ca. $700 \mathrm{~K}$ (a). Variation of the peak current as a function of the square root of the scan rate (b). Variation of the peak potential as a function of the scan rate during cyclic voltammetry (c).

Figure 4: Galvanostatic electrodeposition experiments $(I=1 \mathrm{~mA}, t=30 \mathrm{~min})$ on tungsten electrodes at ca. $700 \mathrm{~K}$ recorded in a) $\mathrm{LiCl}-\mathrm{KCl}_{(\text {eut. })}-0.34 \mathrm{~mol} \% \mathrm{VCl}_{3}$ and b) $\mathrm{LiCl}-\mathrm{KCl}_{\text {(eut.) }}$ $0.34 \mathrm{~mol} \% \mathrm{VCl}_{3}$ and $\mathrm{V}$ metal addition.

Figure 5: SEM images of vanadium deposited on tungsten cathodes from $\mathrm{LiCl}-\mathrm{KCl}-0.34 \mathrm{~mol} \%$ $\mathrm{VCl}_{3}(\mathrm{a}, \mathrm{b})$ and $\mathrm{LiCl}-\mathrm{KCl}-0.34 \mathrm{~mol} \% \mathrm{VCl}_{3}$ with $\mathrm{V}$ metal addition $(\mathrm{c}, \mathrm{d})$.

Figure 6: Photos of electrolytes after solidification. LiCl-KCl-0.34 $\mathrm{mol}^{\circ} \mathrm{VCl}_{3}$ (a) $\mathrm{LiCl}-\mathrm{KCl}-$ $0.34 \mathrm{~mol} \% \mathrm{VCl}_{3}$ with added vanadium metal (b).

Figure 7: Schematic representation of the conditions during electrodeposition of vanadium from LiCl-KCl with predominantly $\mathrm{V}^{2+}$ ions (a) or $\mathrm{V}^{3+}$ ions $(\mathrm{b} ; \mathrm{x} \in\{2,3\})$. The 
concentrations profiles of the ions close to the cathode are represented by straight lines for $\mathrm{V}^{3+}$ and dashed lines for $\mathrm{V}^{2+}$ with vertical arrows indicating the direction of the $\mathrm{V}^{2+}$ concentration changes related to the denoted reactions. In the system with predominantly trivalent vanadium ions competing electrochemical reactions lead to fluctuations of the electrode potential and concentrations of vanadium ions in the vicinity of the electrode (indicated by arrows). 
Table caption:

Table 1: Data for the estimation of the current efficiency $(\varepsilon)$ according to eq. 4 with $M_{\mathrm{V}}=$ $50.94 \mathrm{~g} \mathrm{~mol}^{-1}, \rho_{\mathrm{V}}=6.1 \mathrm{~g} \mathrm{~cm}^{-3}$ 


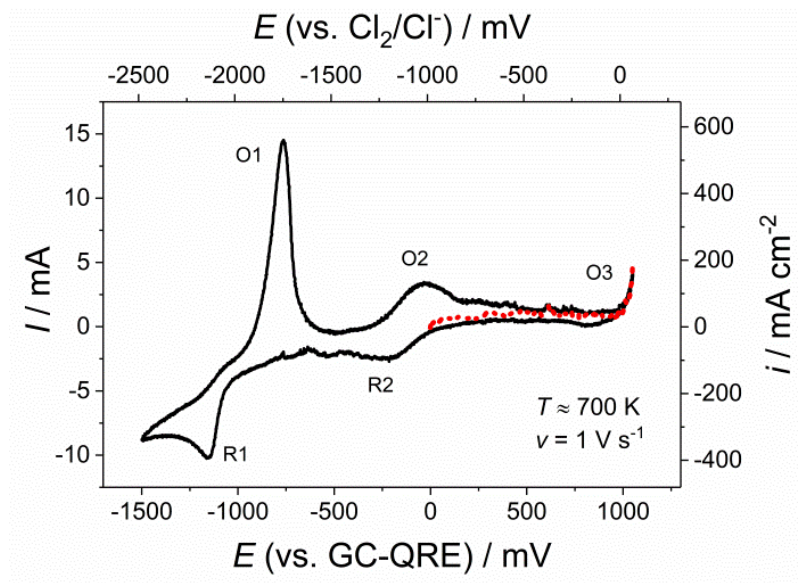

Figure 1: Cyclic voltammogram recorded in $\mathrm{LiCl}-\mathrm{KCl}_{(\text {eut.) }}-0.34 \mathrm{~mol} \% \mathrm{VCl}_{3}$ using a tungsten wire as WE at ca. $700 \mathrm{~K}$. The dotted (red) curve is the first positive scan, in which no considerable current increase could be observed before chlorine evolution (O3), demonstrating that the vanadium ions in the melt are predominantly in the trivalent state. 


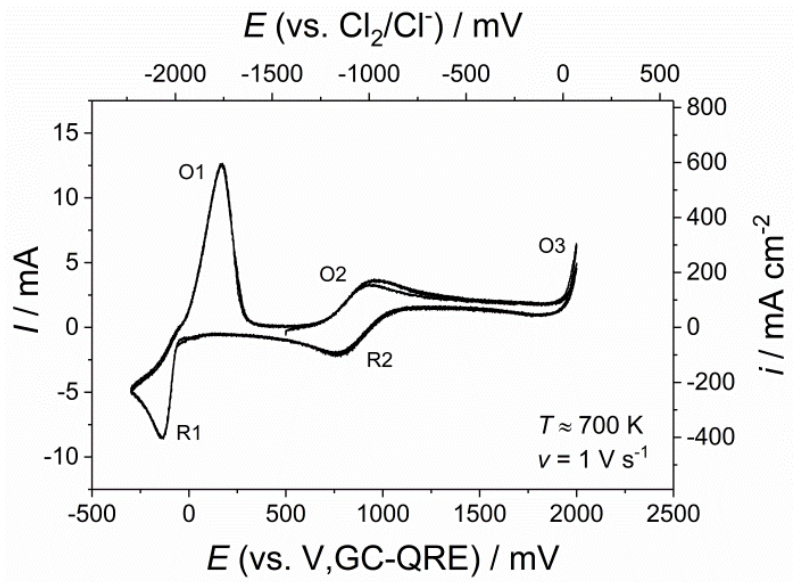

Figure 2: Cyclic voltammogram recorded in $\mathrm{LiCl}-\mathrm{KCl}_{(\mathrm{eut})}-0.34 \mathrm{~mol} \% \mathrm{VCl}_{3}$ using a tungsten wire as WE at ca. $700 \mathrm{~K}$. A metallic $\mathrm{V}$ wire was added to the electrolyte in order to generate divalent vanadium ions. In contact with the GC crucible it determines the potential of the reference electrode (V,GC-QRE) . 

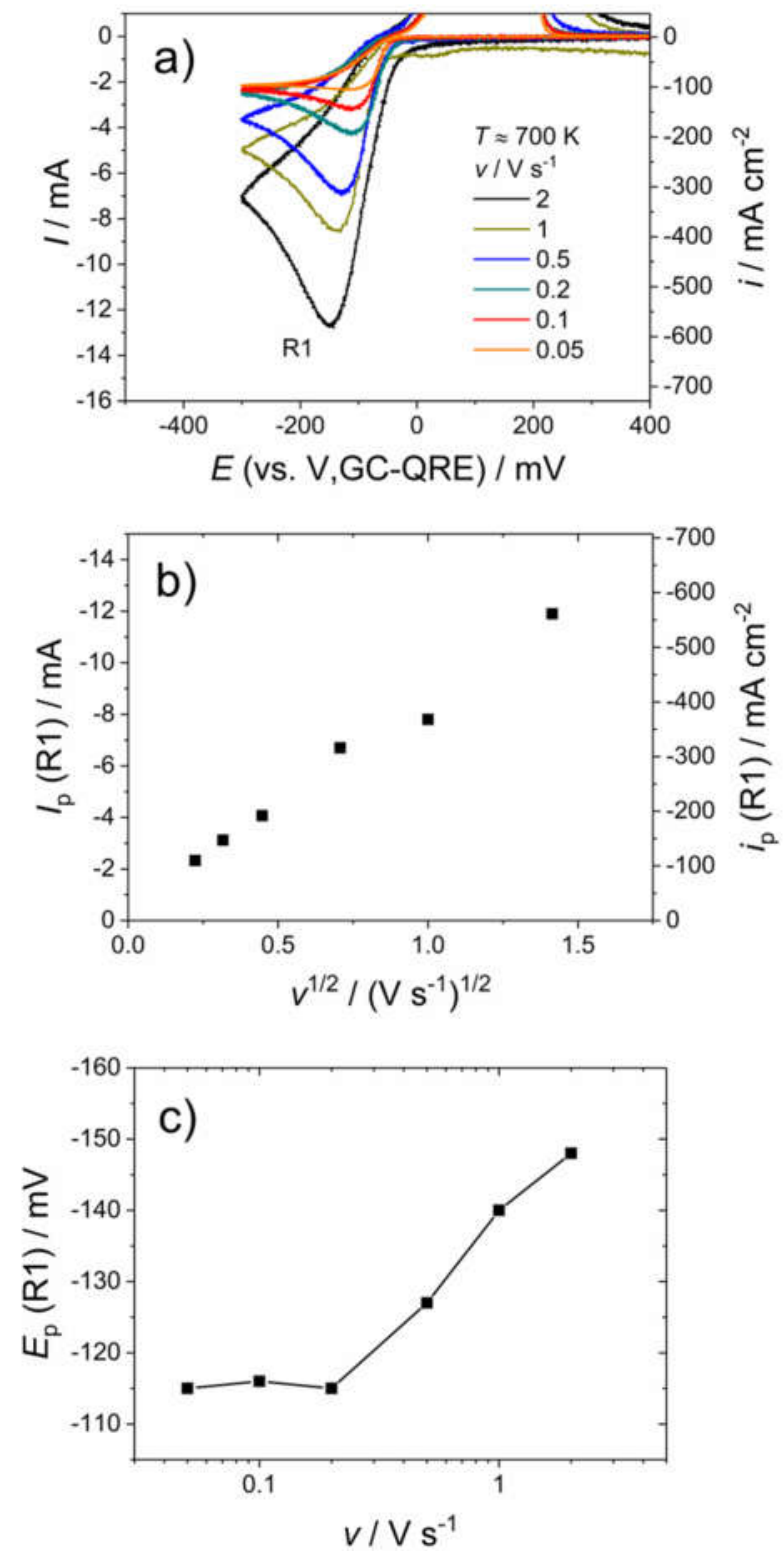

Figure 3: Voltammetric investigation of electrodeposition process in $\mathrm{LiCl}_{-\mathrm{KCl}_{(\mathrm{eut} .)}}-0.34 \mathrm{~mol} \%$ $\mathrm{VCl}_{3}$ with $\mathrm{V}$ metal addition using tungsten wire as $\mathrm{WE}$ at ca. $700 \mathrm{~K}$ (a). Variation of the peak current as a function of the square root of the scan rate (b). Variation of the peak potential as a function of the scan rate during cyclic voltammetry (c). 


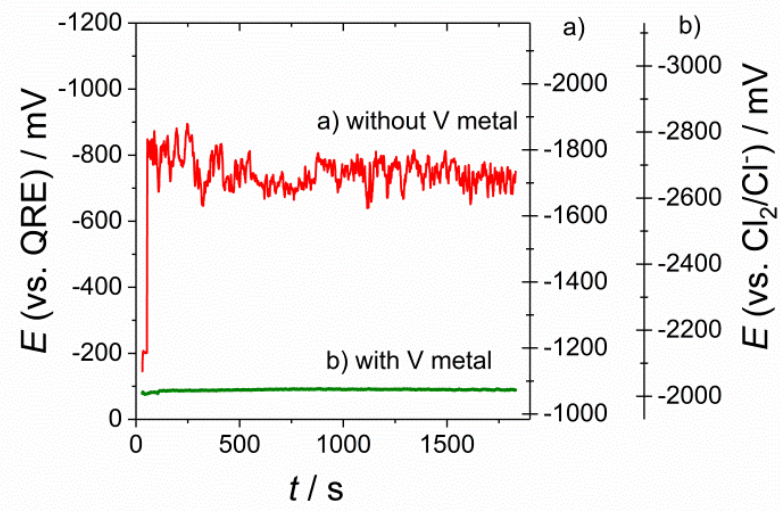

Figure 4: Galvanostatic electrodeposition experiments $(I=1 \mathrm{~mA}, t=30 \mathrm{~min})$ on tungsten electrodes at ca. $700 \mathrm{~K}$ recorded in a) $\mathrm{LiCl}-\mathrm{KCl}_{(\text {(eut.) }}-0.34 \mathrm{~mol} \% \mathrm{VCl}_{3}$ and b) $\mathrm{LiCl}^{-\mathrm{KCl}_{(\text {(eut.) }}-0.34}$ mol\% $\mathrm{VCl}_{3}$ and $\mathrm{V}$ metal addition. 

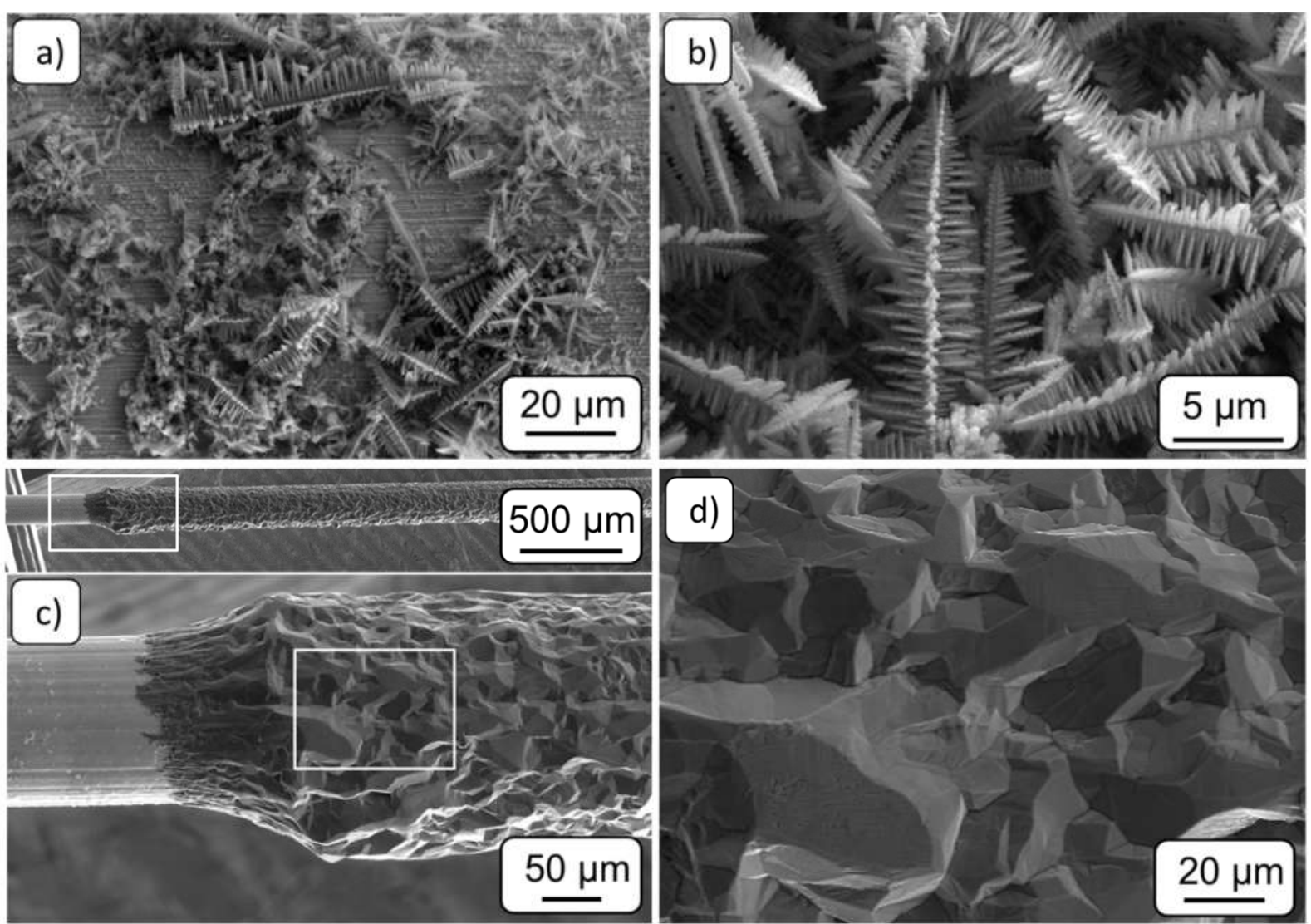

Figure 5: SEM images of vanadium deposited on tungsten cathodes from $\mathrm{LiCl}-\mathrm{KCl}-0.34 \mathrm{~mol} \%$ $\mathrm{VCl}_{3}(\mathrm{a}, \mathrm{b})$ and $\mathrm{LiCl}-\mathrm{KCl}-0.34 \mathrm{~mol} \% \mathrm{VCl}_{3}$ with $\mathrm{V}$ metal addition $(\mathrm{c}, \mathrm{d})$. 


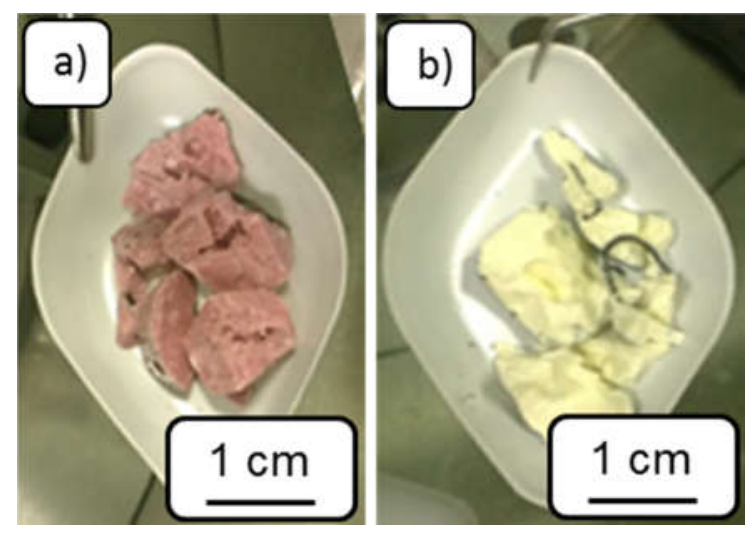

Figure 6: Photos of electrolytes after solidification. $\mathrm{LiCl}-\mathrm{KCl}-0.34 \mathrm{~mol}^{\circ} \mathrm{VCl}_{3}$ (a) $\mathrm{LiCl}-\mathrm{KCl}-$ $0.34 \mathrm{~mol} \% \mathrm{VCl}_{3}$ with added vanadium metal (b). 


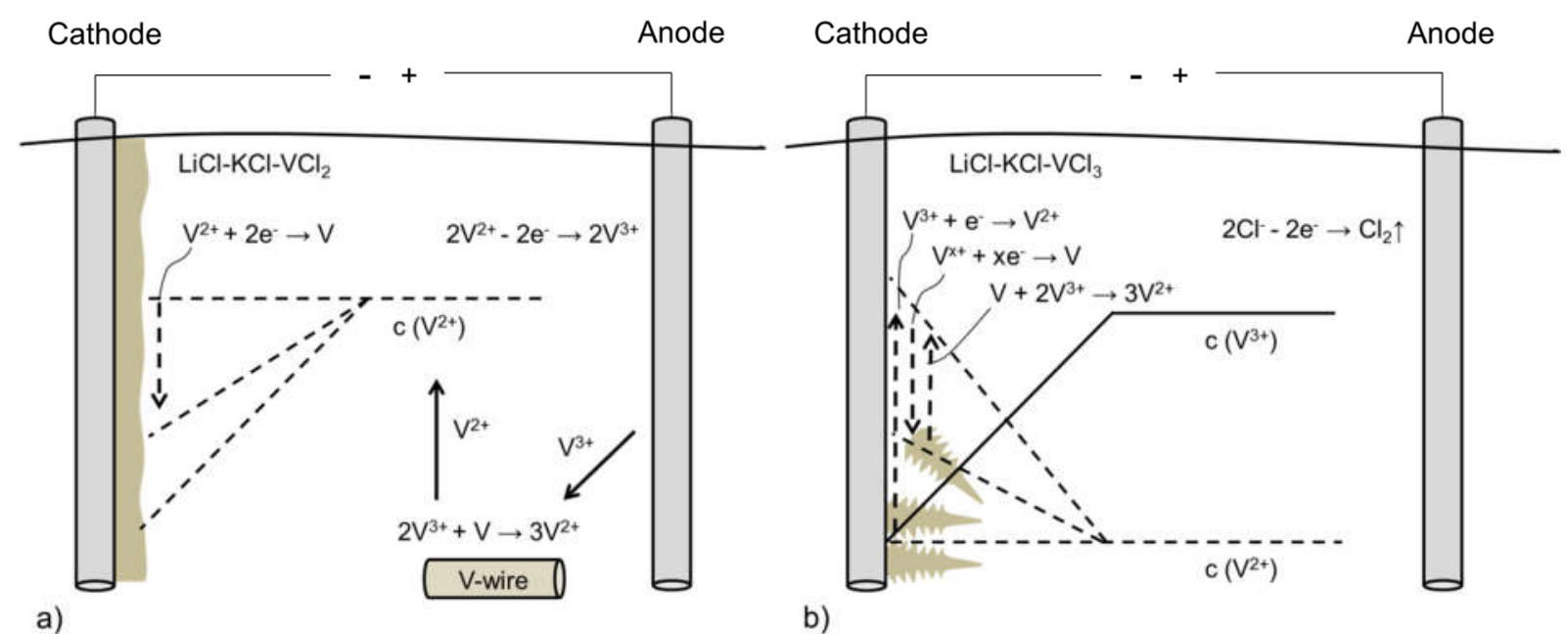

Figure 7: Schematic representation of the conditions during electrodeposition of vanadium from LiCl-KCl with predominantly $\mathrm{V}^{2+}$ ions (a) or $\mathrm{V}^{3+}$ ions $(\mathrm{b} ; \mathrm{x} \in\{2,3\})$. The concentrations profiles of the ions close to the cathode are represented by straight lines for $\mathrm{V}^{3+}$ and dashed lines for $\mathrm{V}^{2+}$ with vertical arrows indicating the direction of the $\mathrm{V}^{2+}$ concentration changes related to the denoted reactions. In the system with predominantly trivalent vanadium ions competing electrochemical reactions lead to fluctuations of the electrode potential and concentrations of vanadium ions in the vicinity of the electrode (indicated by arrows). 
Table 1: Data for the estimation of the current efficiency $(\varepsilon)$ according to eq. 4 with $M_{V}=50.94$ $\mathrm{g} \mathrm{mol}^{-1}, \rho_{\mathrm{V}}=6.1 \mathrm{~g} \mathrm{~cm}^{-3}$

\begin{tabular}{llllllllll}
\hline No. & $I /$ & $t /$ & $d /$ & $L /$ & $\begin{array}{l}V_{\text {coat }} / \\
\mathrm{mm}^{-3}\end{array}$ & $\begin{array}{l}m_{\text {coat }} / \\
\mathrm{mg}\end{array}$ & $\begin{array}{l}V_{\text {calc }} / \\
\mathrm{mm}^{-3}\end{array}$ & $\begin{array}{l}m_{\text {calc }} / \\
\mathrm{mg}\end{array}$ & $\varepsilon$ \\
\hline 1 & 1 & 0.5 & 0.21 & 5.1 & 0.085 & 0.52 & 0.078 & 0.48 & 1.09 \\
2 & 1 & 2 & 0.35 & 4.5 & 0.341 & 2.1 & 0.311 & 1.9 & 1.10 \\
3 & 1 & 2 & 0.31 & 5.2 & 0.298 & 1.8 & 0.311 & 1.9 & 0.96 \\
\hline
\end{tabular}

